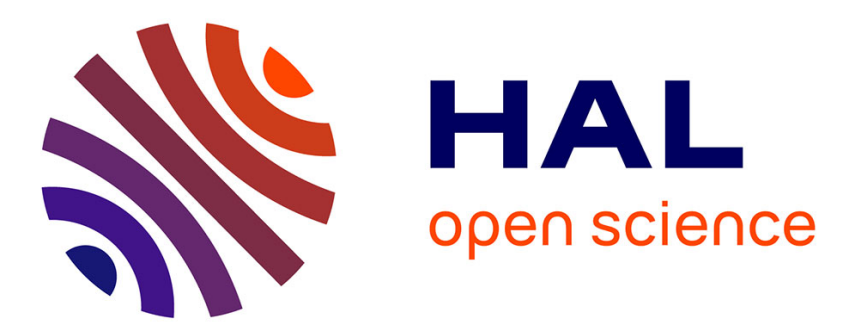

\title{
Using mechanical-acoustical reciprocity for diagnosis of structure borne sound in vehicles
}

\author{
P.J.G. van Der Linden, J. Fun
}

\section{To cite this version:}

P.J.G. van Der Linden, J. Fun. Using mechanical-acoustical reciprocity for diagnosis of structure borne sound in vehicles. Journal de Physique IV Proceedings, 1994, 04 (C5), pp.C5-93-C5-96. 10.1051/jp4:1994513 . jpa-00252806

\section{HAL Id: jpa-00252806 https://hal.science/jpa-00252806}

Submitted on 1 Jan 1994

HAL is a multi-disciplinary open access archive for the deposit and dissemination of scientific research documents, whether they are published or not. The documents may come from teaching and research institutions in France or abroad, or from public or private research centers.
L'archive ouverte pluridisciplinaire HAL, est destinée au dépôt et à la diffusion de documents scientifiques de niveau recherche, publiés ou non, émanant des établissements d'enseignement et de recherche français ou étrangers, des laboratoires publics ou privés. 


\title{
Using mechanical-acoustical reciprocity for diagnosis of structure borne sound in vehicles
}

\author{
P.J.G. VAN DER LINDEN and J.K. FUN*
}

LMS International, Interleuvenlaan 68, 3001 Leuven, Belgium

${ }^{*}$ NedCar Engineering \& Development b.v., Steenoverweg 1, 5700 MC Helmond, The Netherlands

\begin{abstract}
The low frequency interior noise in cars is for a large part the result of structure borne excitation. The transfer of the structure borne sound involves a large number of components of the engine suspension, wheel suspension and chassis which are all potentially contributing to the overall noise level. This process can be analyzed through a combination of transfer function measurements with operational measurements under normal vehicle conditions.

This technique, called transfer path analysis, requires large numbers of transfer function measurements with excitation of the body or cabin at the rubber mountings. Unfortunately, bad access to these crucial measurement locations causes either high instrumentation and measurement effort or less accurate measurement data.

The practicality and quality of the measurements can be improved by using reciprocal measurements for the mechano-acoustic transfer of the body or cabin structure; a loudspeaker in the cavity is used for the reciprocal excitation. The reciprocity technique also allows better insight in the acoustic response of the cavity.
\end{abstract}

\section{BACKGROUND; STRUCTURE BORNE SOUND}

The low frequency noise inside road vehicles is subject to considerable development. To improve the comfort for the occupants the noise levels are reduced and the sound quality is optimised.

A large part of the development effort is directed at reduction of the structure borne sound. To analyse the importance of components and mountings (like engine mountings, exhaust, steering system, wheel suspension etc) the method of transfer path analysis is applied. The transfer path techniques involves a large number of mechanical-acoustic transfer function measurements. The use of reciprocity for these measurements will be presented.

\section{TRANSFER PATH ANALYSIS}

The structure borne sound process can be analysed through the combination of transfer function measurements with operational measurements of vibrations and sound pressures under normal road conditions of the vehicle [3]. This method is called transfer path analysis and it has the capability to quantify the sound pressure contribution of each attachment point of a mechanical component in each direction separately.

There are two basic steps in transfer path analysis:

1. Estimation of the operational forces at the attachments or mountings.

2. Combining the operational forces with mechanical - acoustic transfer functions which relate the forces to sound pressure at the occupants ears.

For the first step in the analysis the forces are estimated on the basis of system characteristics and acceleration measurements at the mountings.

The second step in the analysis involves measurements of the relation between forces and sound pressure; the mechanical-acoustic transfer functions :

$$
H_{m a_{i j k}}=\frac{p_{k}}{f_{i j}} \quad\left(m^{-2}\right)
$$


Traditionally these functions are measured with an impact hammer equipped with a force sensor, while microphones are placed at the occupant ear locations. Subsequently all mountings are excited in three directions and the transfer functions to the interior microphones are measured.

The partial sound pressure $p_{i j k}$ is calculated as follows

$$
p_{i j k}=H_{m a i j k} f_{i j} \quad\left(N / m^{2}\right)
$$

\section{MECHANICAL-ACOUSTIC RECIPROCITY}

It can be interesting to use an alternative approach for the measurements of mechanical-acoustic transfer functions; reciprocal measurements.

The response of structures and sound fields can be reciprocal. This basically means that the same relations between input and output quantities are measured when the excitation energy is brought into the system at what is normally the output side. In the literature several applications of reciprocal measurements on a wide range of constructions, from production machinery to aircrafts, have been reported [1,2]. For mechanical-acoustic transfer function measurements on car body, truck cabins, etc. the following relation is used:

$$
\left.\frac{P_{k}}{f_{i j}}\right|_{Q_{k=0}}=\left.\frac{-\ddot{X}_{i j}^{*}}{\dot{Q}_{k}^{*}}\right|_{f_{i j=0}^{*}}
$$

with

$$
\underset{*}{Q_{k}}
$$

volume velocity at microphone location $\mathrm{k}\left(\mathrm{m}^{3} / \mathrm{s}\right)$

reciprocal quantity

The system is excited by an acoustic source in the cabin and the responses are measured as accelerations at the mountings. The practical advantage of this approach is that the accelerometers at the mountings for the operational measurements can again be used for the transfer function measurements. Another advantage is that a large number of transfer functions can be measured simultaneously; to several mountings in all directions.

A basic requirement for reciprocity is linearity. The sound field in the cavity is usually found to be linear in the range of sound pressures during operation and transfer function measurements. But the linearity of the structure (cabin, body or chassis) is less evident, non-linear stiffness effects and friction damping can cause deviations.

Fig. $1: H_{m a}$ linearity with direct excitation
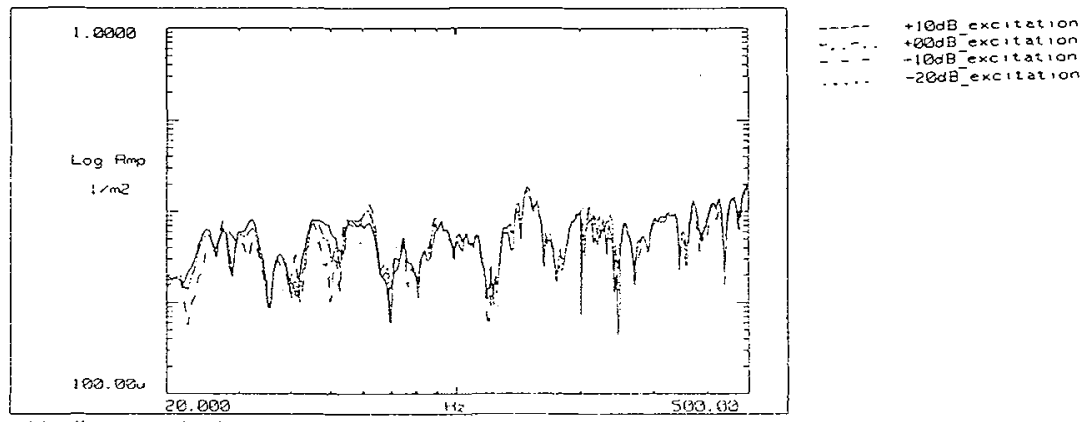

This can be critical since linearisation around normal working conditions will not take place. The velocity amplitudes in the cavity and in the structure will differ even more from normal operation during reciprocal $H_{m a}$ measurement than during classical direct measurement.

Fortunately it is found in measurements that the linearity of direct and reciprocal $H_{\text {mia }}$ measurement is acceptable. Fig. 1 shows direct $H_{m a}$ measurements over a $30 \mathrm{~dB}$ excitation range. The deviation of the peak values remains less than $3 \mathrm{~dB}$ between 30 and $500 \mathrm{~Hz}$. For the reciprocal measurements the linearity is even better. 
The next important requirement concerns the conditions given in equation (3). In a direct measurement the volume velocity at the receiving microphones should approximate zero. This condition is easily met by all modern condenser microphones. The second condition that the force at the mountings should approximate zero is equally necessary for reciprocal and direct measurements. This condition has more serious consequences. It means that the mountings should be decoupled during the measurements, as a result a cumbersome dismounting of the driveline and wheel suspensions is necessary. The influence of the mounting on the $H_{m a}$ is equal for reciprocal and direct measurements.

In practice it is in some cases possible to measure with attached mountings. The mountings must then be relatively compliant, like rubber bushing and elastic couplings. If the mounting remains coupled the following condition should be met:

$$
K<\frac{\omega^{2}}{H_{m m}} \quad(N / m)
$$

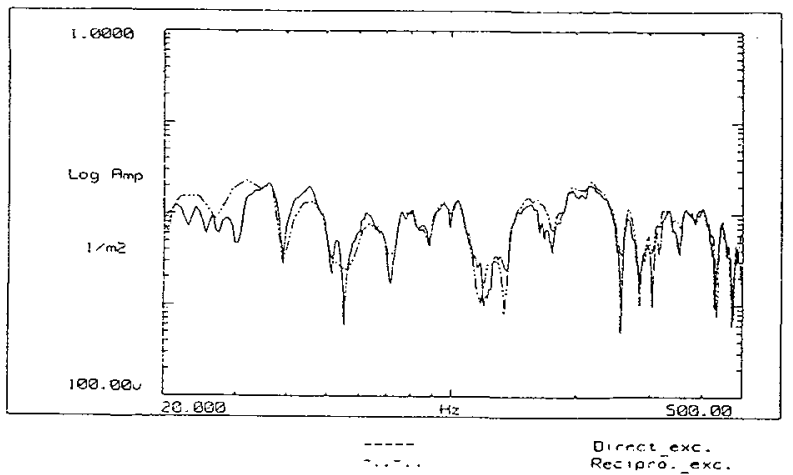

Fig. 2 : Comparison of direct and reciprocal $H_{m a}$ measurements

The final comparison between direct and reciprocal measurement shows agreements better than $3 \mathrm{~dB}$ between 40 and $400 \mathrm{~Hz}$, figure 2 shows an example. The deviations remain less than $3 \mathrm{~dB}$ on the maxima between 40 and $400 \mathrm{~Hz}$. The differences below $50 \mathrm{~Hz}$ seem to be related to the limited linearity. The agreement becomes better when the direct measurement at very low force levels is used. The differences at higher frequencies are more related to the accuracy of direct force measurements.

\section{ADDITIONAL ANALYSIS OF THE CABIN ACOUSTICS}

With the availability of calibrated volume velocity source it is possible to measure acoustic transfer functions inside the cabin (see fig. 7):

$$
H_{a a k l}=\frac{P_{k}}{q_{i}} \quad(N m / s)
$$

with $\quad q_{i} \quad:$ volume velocity at cavity location $!\left(\mathrm{m}^{3} / \mathrm{s}\right)$

These transfer functions indicate the effectiveness at which a body panel can contribute to the sound pressure at the occupants ear.

It is sometimes possible to relate the maxima in $H_{m a}$ functions to maxima in the acoustic transfer functions. An example is given in fig. 4 which shows correlation between maxima in $H_{m a}$ at 61,105 and $250 \mathrm{~Hz}$ with acoustic resonances in the cavity volume. 


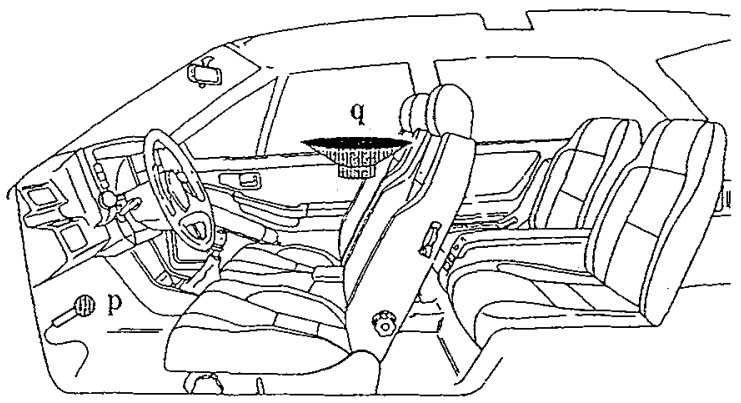

Fig. 3 : The acoustic transfer function measurement

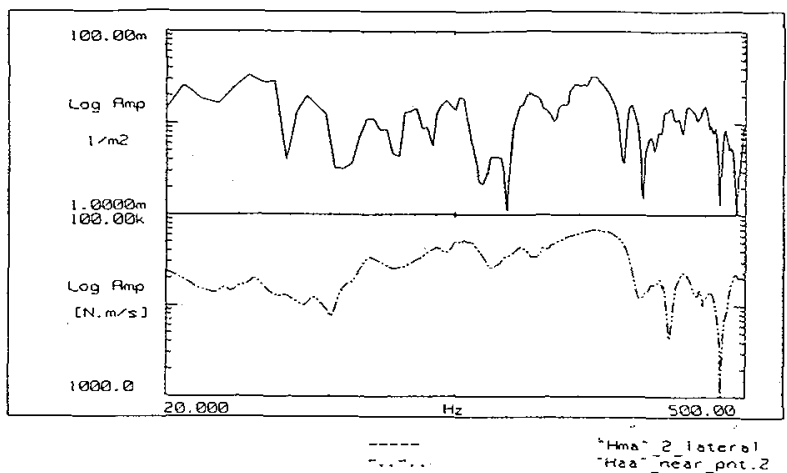

Fig. 4 : Comparison of the acoustic transfer function inside the cabin to the mechanical-acoustic transfer function

\section{CONCLUSION}

The use of reciprocal mechanical - acoustic transfer function measurements is discussed for structure borne sound diagnosis. It is found that mechanical-acoustic reciprocity is valid for vehicle bodies; sufficiently accurate results can be obtained in the most relevant frequency range between 30 and $500 \mathrm{~Hz}$.

The specific advantages of reciprocal mechanical-acoustic transfer function measurement are :

- The attachment points are instrumented with accelerometers only.

This requires minimal space and the same sensors can be used for the operational measurements.

- A functional advantage is that the acoustic impedance in the cabin and acoustic transfer functions inside the cabin can be measured to relate mechanical - acoustic sensitivity to acoustic sensitivity of the cabin.

- $\quad$ Given the equipment, all attachment points and directions can be measured simultaneously, which is much faster than exciting all attachment DOFs one after the other.

- It becomes feasible to warm up the vehicle to normal operating temperatures, stop the engine and measure the transfer functions immediately after. This can be necessary for engine or exhaust related paths.

- The repeatibility is improved compared to direct hammer impact measurements.

The acoustic transfer functions have the potential to be used for identification of the dominant radiating surfaces inside the cavity at low frequencies. This method is in development, its application is not limited to structure borne sources.

\section{REFERENCES}

[1] Multipath sound transfer from resiliently mounted shipboard machinery; J.W. Verheij, Ph.D. Thesis Technische Physische Dienst TNO-TPD Delft, 1982.

[2] The reciprocity principle and applications in vibro-acoustics; F.J. Fahy, Proceedings of the second international congress on recent developments in air-and structure-borne sound and vibration, 1992, p 611-618.

[3] Suspension analysis in view of road noise optimisation; W. Hendricx and D. Vandenbroeck, Proceedings of the SAE 1993 Conference, Traverse City, 10-13/05/1993. 